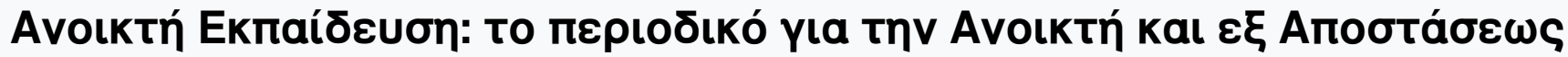

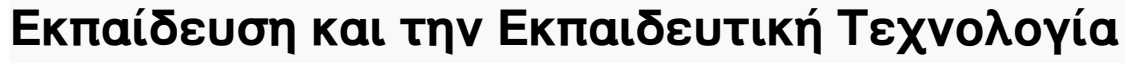

Tóp. 7, Ap. 2 (2011)

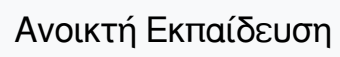

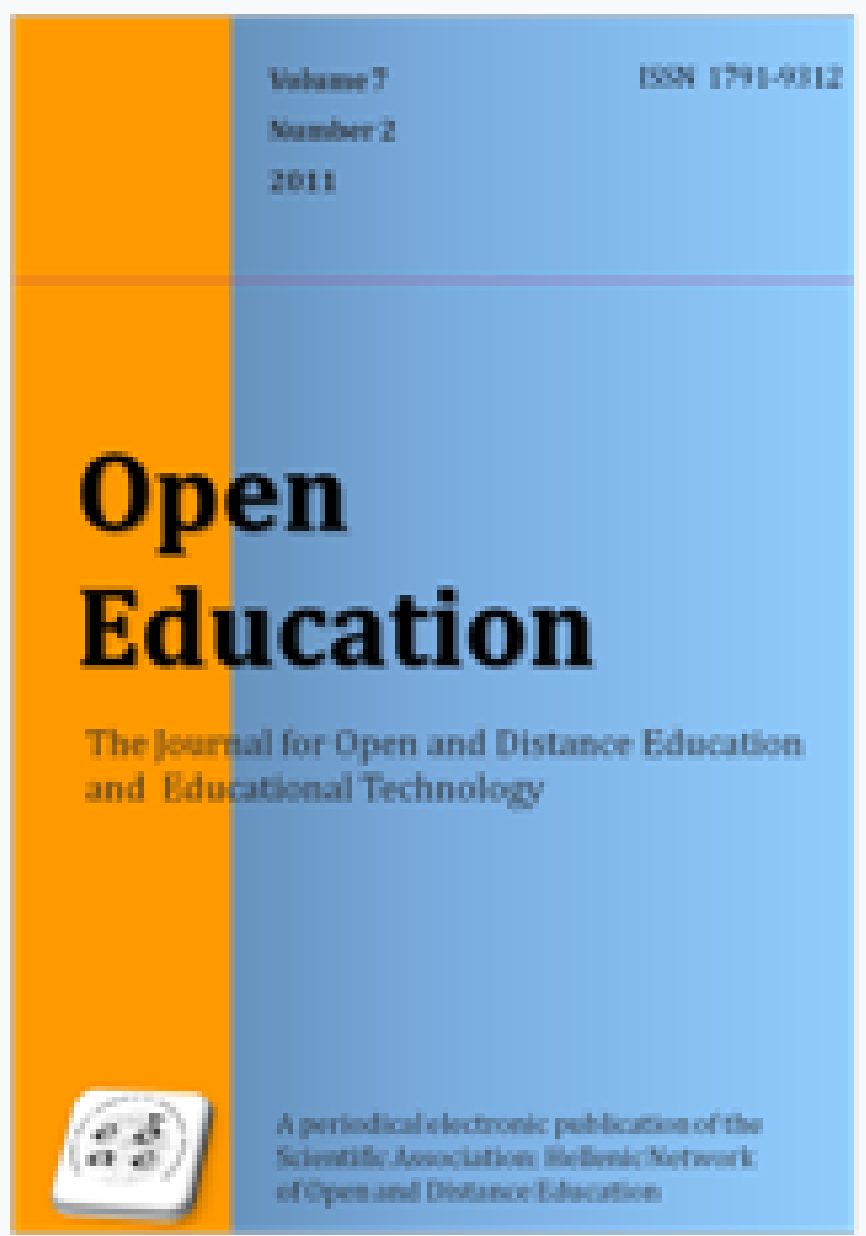

Hellenic Open University student views on Supplementary Digitized Educational Material

Vassilia Hatzinikita, Athanasios Katsis, Konstantinos Petrogiannis

doi: $10.12681 /$ jode. 9774

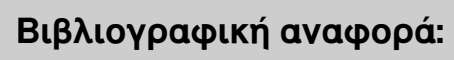




\title{
Hellenic Open University student views on Supplementary Digitized Educational Material
}

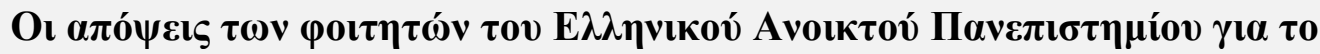

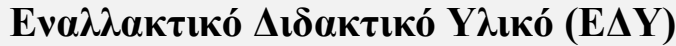

\author{
Vassilia Hatzinikita, \\ Hellenic Open University, \\ School of Humanities, \\ Professor, \\ hatzinikita@eap.gr \\ Athanasios Katsis, \\ University of Peloponnese, \\ Department of Social and Educational Policy, \\ Associate Professor \\ katsis@uop.gr \\ Konstantinos Petrogiannis, \\ Hellenic Open University, \\ School of Humanities, \\ Associate Professor, \\ kpetrogi@psed.duth.gr
}

\begin{abstract}
The paper presents a part of an evaluation study undertaken by the Hellenic Open University (HOU) regarding the design and implementation of Supplementary Digitized Educational Material (SDEM: Video, Hypertext, Webcast) which was developed in order to support a number of undergraduate and postgraduate modules. The aim of this paper is to examine the HOU students' views about the quality of each module's SDEM they used during their study. More specifically, students' views about (a) content presentation (b) instructional and pedagogical methodology (c) technical specifications and (d) quality of interface of the SDEM were studied by adopting a quantitative approach. The relevant data were selected with the use of an online-based questionnaire, specifically developed for this evaluation study, administered through a user-friendly web application form. The research findings indicated that students consider Hypertext as the least effective mode of digitized material whereas Webcast is viewed most favourably especially in the pedagogical dimension. Finally, postgraduate students face more serious challenges than undergraduates not only in the pedagogical aspect but also in terms of the SDEM's technical specifications.
\end{abstract}

\section{Keywords}

Distance Education, Evaluation, Hellenic Open University, Higher Education, Students' Views, Supplementary Digitized Educational Material (SDEM)

\section{Introduction}

During its first years of operation the Hellenic Open University (HOU) provided distance learning higher education studies relying almost exclusively on print-based material. Following that initial phase and bearing in mind the central role that educational material plays in distance education (Holmberg, 1989; Koustourakis, Panagiotakopoulos \& Vergidis, 2008; Lionarakis, 2001; Pierrakeas, Xenos, Pintelas, 
2003), the HOU implemented an important developmental project in order to support the available teaching material with the inclusion of a newly developed alternative type of material that would supplement the books and study-guides. The project resulted in the design and implementation of Supplementary Digitized Educational Material (SDEM) in the form of Video, Hypertext, and Webcast sessions.

The programmatic objective of SDEM was to complement the existing printed material creating a whole cohesive educational package for a number of undergraduate and postgraduate modules ${ }^{1}$ (Lykourgiotis, 2002). In addition, the aim of a successful SDEM development was the improvement of the established

instructional processes at the HOU as well as the HOU's international reputation in distance learning in the higher education field (Lykourgiotis, 2002).

Following the development and production of SDEM for a considerable number of modules and its inclusion in the educational package provided to the students, the HOU proceeded to the next step, one which should follow the development of any newly developed educational material. This step included the evaluation procedure ${ }^{2}$ which was implemented in the context of Action 9 of the Project: "Development and improvement of the services provided by the Hellenic Open University".

This particular evaluation is the first systematic internal evaluation for educational material that has been implemented by the HOU. Furthermore, both SDEM's production and inclusion in the educational package of a considerable number of modules reaching a significant part of the undergraduate and postgraduate student population, as well as its evaluation comprise an innovative task on its own. This particular procedure appears to be unique among all the other tertiary institutions of the country in the field of development and evaluation of digitized instructional material. Despite the fact that this innovative task is a necessity that stems from the conditions of distance learning education that characterize the educational methodology adopted by the HOU, the procedure itself may serve prospectively as "good practice" for the development of digitized instructional material used by the conventional higher education institutions in the country. Therefore, the evaluation of SDEM material was regarded as particularly important since it revealed both the positive elements and the weaknesses of existing SDEM with a view to improving its quality in the near future.

The demands of the evaluation project in relation to the restrictions that had been set forth by the EPEAEK ${ }^{3}$ context led to the adoption of a type of evaluation with the following characteristics: (a) the whole procedure was an institutionalized form of internal evaluation (Barbier, 1985) within the HOU; (b) a form of summative evaluation (Scriven, 1967) was selected for this procedure, that is a final assessment in order to evaluate the learning outcome from the use of SDEM by the students, so that, in a next step, HOU will take the necessary strategic decisions for the improvement of SDEM quality.

In this paper only a part of the whole evaluation study regarding the SDEM is presented in order to reveal critical findings of this project. More specifically, this paper presents the HOU students' views on SDEM quality for a number of interrelated dimensions. These dimensions are regarded -according to the review of the relevant literature (e.g. Ministry of Education - Pedagogical Institute, 1999; Mikropoulos, 2000; Komis \& Mikropoulos, 2001; Panagiotakopoulos, Pierrakeas \& Pintelas, 2005) - as critical components of the quality of the SDEM, namely: (i) the presentation of the content of the SDEM, (ii) its instructional and pedagogical methodology, (iii) the kind of interaction and the interface environment of the SDEM, and (iv) its technical specifications. Moreover, the study examined whether there was 
a relationship between students' views concerning SDEM quality with (a) the type of SDEM (Webcast, Video, Hypertext) and (b) the level of the students' studies (undergraduate, postgraduate).

\section{Method}

The methodological approach for SDEM evaluation ${ }^{4}$ was based on the previously mentioned dimensions that had been identified through the review of the relevant literature ${ }^{5}$. In these studies, both quantitative and qualitative strategies were applied although there is a trend towards the latter. For the final selection of the most suitable approach a number of limitations or restrictions specified in the EPEAEK technical context were taken into consideration.

A mixed evaluation design was finally adopted as the most suitable for the case. The decision was justified by the fact that this approach could make use of the positive aspects of both the qualitative and quantitative strategies (Burgess, 1985; Cohen, Manion, \& Morrison, 2007; Denzin \& Lincoln, 1998 a, b, 1994; Hammersley, 1993, 1989; Johnson \& Christensen, 2004; Patton, 1991; Robson, 2007) and restrict their negative components satisfying the necessary requirements so that the evaluation procedure would be applied in the most valid, reliable and objective way. However, in this paper only the relevant quantitative parts of the study are presented.

\subsection{The material}

The evaluated SDEM was part of the educational material of 21 modules (14 undergraduate and 7 postgraduate) belonging to two undergraduate and three postgraduate study programs ${ }^{6}$. It was produced by the HOU, and was provided to the students during the academic year 2006-7. It included 44 titles comprising 29 Videos, 8 Hypertext applications and 322 Webcast sessions.

\subsection{The evaluation instrument}

Initially, for each of the four dimensions of SDEM quality, their conceptual content was further adjusted for each specific SDEM type (Video, Hypertext and Webcast) providing in this way the appropriate operational context of evaluation. The initial version of the questionnaire was available for the students of two modules as a pilotstudy trial. In addition, it was examined by a body of experts in the field of educational software evaluation, thus establishing the instrument's construction validity.

For the evaluation of this material by the HOU students a questionnaire was devised specifically for the needs of this part of the evaluation project. The questionnaire was based on the findings of a study using semi-structured interviews with a number of the HOU module coordinators carried out in an initial step of this evaluation project. Moreover, it was decided that the most efficient strategy for the questionnaire administration would be an online version in a user-friendly web application form designed and implemented by the informatics team (HOU, 2008).

There were different versions of the questionnaire developed for each module according to the particular features of SDEM type (Webcast, Video, Hypertext). The final version of the questionnaire was organized in five thematic parts. The first part included questions about the socio-demographic and academic background of the respondents supplemented by the HOU's Registry Office data. The remaining parts (2-5) included 64 items in a five-point Likert-type scale (1 indicated the stronger negative and 5 the stronger positive response) and 9 dichotomous items (yes-no type). 
The items were devised to reflect the four dimensions regarding SDEM quality evaluation. The description of each dimension with some sample questions are presented as follows:

- $2^{\text {nd }}$ part (content presentation): It included questions concerning the evaluation of the presentation of the content of each SDEM type of the selected modules (item examples: Is SDEM content comprehensible? Is the content of printbased material in concurrence with the content of SDEM? Does the printed or other teaching material provide you with the prerequisite knowledge in order to understand the specific SDEM? How accurate and clear is the information provided by SDEM? Is there consistency in the way the various terms and symbols are used in SDEM?).

- $3^{\text {rd }}$ part (instructional and pedagogical methodology): It focused on the evaluation of instructional and pedagogical methodology aspects (item examples: Are the learning objectives explicitly stated? Does SDEM place emphasis on core concepts? Do you think that SDEM's learning objectives are met? Does SDEM support the active approach to learning? Does SDEM support critical thought? Does SDEM provide self-evaluation activities? In the case of "wrong" answers does SDEM provide feedback?).

- $4^{\text {th }}$ part (technical characteristics and specifications): It put emphasis on the technical characteristics and specifications (item examples: Is SDEM accompanied by a user's manual? Are the technical terms of the manual explained? Is SDEM's installation procedure easy? Is SDEM accompanied by the minimum hardware requirements with regard to the installation procedure?

- $5^{\text {th }}$ part (interface): The students evaluated the look-and-feel of the SDEM interface (item example: Is the SDEM screen layout appealing? Is the navigation of the SDEM easy? Do the SDEM multimedia features distract the student's attention from its content? Is the access to the menu easy?).

A series of internal consistency controls using the Cronbach alpha $(\alpha)$ coefficient were conducted for the questions of the $2^{\text {nd }}$ to $5^{\text {th }}$ part in order to confirm whether each group of questions constituted homogenous dimensions. Based on these results an overall aggregated score for each part could be calculated for further statistical analyses.

The analyses, both for the whole sample (see Table 1) and separately according to the modules, the type of the SDEM, and the level of studies (all the coefficients were ranged well above .65), confirmed the groupings of the questions suggesting that there is a strong association among the individual questions that constitute each part and indicating that they stand as separate factors.

Table 1

Internal consistency coefficients of the evaluation questionnaire's thematic parts of SDEM

\section{Focus of the thematic parts}

alphas

(a)

Part 2 (8 questions): SDEM content presentation

Part 3 (29 questions): SDEM instructional and pedagogical methodology

Part 4 (12 questions): SDEM technical characteristics and specifications 


\subsection{Participants and procedure}

According to the evaluation study plan the target-population included 3349 students who, during the academic year 2006-07, had been provided with and used SDEM as part of their educational package and were consequently able to evaluate it. In order to ensure maximum participation, the coordinators and tutors of the selected modules informed the students of their groups and a platform of online information, reminding notes and follow-up procedures was developed. Weekly reports recorded the flow of questionnaire completion by the students and when necessary a reminding email was sent.

The repeated announcements on the internet and the reminding emails to the target population resulted in a sample of 463 undergraduate and postgraduate students (mean age: 37, s.d.: 6.8, range: 24-68) registered in 21 modules who completed 544 questionnaires in total. The different number is due to the fact that a number of respondents completed more than one questionnaire since they had registered in different modules and consequently had the opportunity to evaluate different SDEM types. The sample size is deemed appropriate for generalization of the results since it involved an adequate population participation rate covering all modules, albeit at various levels.

Almost $80 \%$ of the respondents were undergraduate students with males slightly outnumbering female students (52\% to $48 \%$ respectively). With regard to the 544 completed questionnaires, 435 of them referred to SDEM of undergraduate and 109 of postgraduate modules. Finally, 246 questionnaires evaluated Videos, 193 Webcasts, and 105 Hypertexts. Data were analysed employing descriptive and inferential statistical techniques. The statistical significance level was set at 0.05.

\section{Results}

The results presented in this section are based on the four dimensions of the research instrument outlined in Table 1. Moreover, additional aspects of the analysis focus on the type of SDEM (Webcast, Video, Hypertext) and the level of students' studies (undergraduate, postgraduate).

\subsection{The overall picture}

Table 2 presents mean and standard deviations of the four dimensions of SDEM quality evaluated by the students. According to these results students appear to consider the SDEM pedagogical component as the least positive one.

\section{Table 2}

\section{Descriptive measures of the four thematic parts}

\begin{tabular}{|l|c|c|c|}
\hline & $\mathrm{N}$ & Mean & $\begin{array}{l}\text { Standard } \\
\text { deviation }\end{array}$ \\
\hline $\begin{array}{l}\text { SDEM content } \\
\text { presentation }\end{array}$ & 525 & 3.57 & 0.71 \\
\hline $\begin{array}{l}\text { SDEM instructional and } \\
\text { pedagogical } \\
\text { methodology }\end{array}$ & 516 & 3.36 & 0.89 \\
\hline $\begin{array}{l}\text { SDEM technical } \\
\text { characteristics and } \\
\text { specifications }\end{array}$ & 493 & 3.62 & 0.85 \\
\hline
\end{tabular}




\begin{tabular}{|l|l|l|l|}
\hline SDEM interface & 493 & 3.59 & 0.78 \\
\hline
\end{tabular}

A statistical test (t-test) displayed statistically significant differences regarding SDEM interface between undergraduate and postgraduate students (see Table 3). However, utilizing Cohen's d, we note that there is a considerable difference as well in the technical characteristics and specifications part. In both cases undergraduates provide a more favorable view of SDEM interface and technical characteristics.

Table 3

Statistical analysis of the four thematic parts between undergraduate and postgraduate students

\begin{tabular}{|c|c|c|c|c|c|c|}
\hline 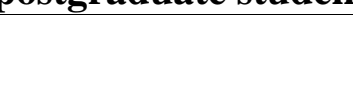 & Level of study & $N$ & Mean & $\begin{array}{l}\text { Standard } \\
\text { deviation }\end{array}$ & $p$ & $\begin{array}{c}\text { Cohen's } \\
d\end{array}$ \\
\hline \multirow{2}{*}{$\begin{array}{l}\text { SDEM content } \\
\text { presentation }\end{array}$} & Undergraduate & 420 & 3.59 & 0.65 & \multirow{2}{*}{0.435} & \multirow{2}{*}{0.10} \\
\hline & Postgraduate & 99 & 3.52 & 0.91 & & \\
\hline \multirow{2}{*}{$\begin{array}{l}\text { SDEM instructional } \\
\text { and pedagogical } \\
\text { methodology }\end{array}$} & Undergraduate & 412 & 3.41 & 0.83 & \multirow[b]{2}{*}{0.12} & \multirow[b]{2}{*}{0.20} \\
\hline & Postgraduate & 98 & 3.23 & 1.08 & & \\
\hline \multirow{2}{*}{$\begin{array}{l}\text { SDEM technical } \\
\text { characteristics and } \\
\text { specifications }\end{array}$} & Undergraduate & 401 & 3.66 & 0.80 & \multirow[b]{2}{*}{0.071} & \multirow[b]{2}{*}{0.49} \\
\hline & Postgraduate & 87 & 3.44 & 1.04 & & \\
\hline \multirow[t]{2}{*}{ SDEM interface } & Undergraduate & 398 & 3.67 & 0.72 & \multirow{2}{*}{$<0.0001$} & \multirow{2}{*}{0.49} \\
\hline & Postgraduate & 90 & 3.28 & 0.94 & & \\
\hline
\end{tabular}

The differences among the three types of SDEM are presented in Table 4. The statistical analysis (one-way ANOVA) demonstrated statistically significant differences among all parts with the most pronounced ones being in the content and pedagogical parts. In both of these parts students' views are much more favorable about Webcast and Video than Hypertext. There are more balanced responses concerning the technical specifications and the interface.

Table 4

Statistical analysis of the four thematic parts among SDEM types

\begin{tabular}{|c|c|c|c|c|c|}
\hline & Level of study & $N$ & Mean & $\begin{array}{l}\text { Standard } \\
\text { deviation }\end{array}$ & $p$ \\
\hline \multirow{3}{*}{$\begin{array}{l}\text { SDEM content } \\
\text { presentation }\end{array}$} & Webcast & 188 & 3,66 & ,73120 & \multirow{3}{*}{0.003} \\
\hline & Video & 235 & 3,59 & ,60333 & \\
\hline & Hypertext & 102 & 3,37 & ,85799 & \\
\hline \multirow{3}{*}{$\begin{array}{l}\text { SDEM instructional } \\
\text { and pedagogical } \\
\text { methodology }\end{array}$} & Webcast & 182 & 3,43 & ,89538 & \multirow{3}{*}{$<0.0001$} \\
\hline & Video & 233 & 3,45 & ,76675 & \\
\hline & Hypertext & 101 & 3,05 & 1,08153 & \\
\hline \multirow{3}{*}{$\begin{array}{l}\text { SDEM technical } \\
\text { characteristics and } \\
\text { specifications }\end{array}$} & Webcast & 180 & 3,67 & ,77075 & \multirow{3}{*}{0.046} \\
\hline & Video & 220 & 3,53 & 87746 & \\
\hline & Hypertext & 93 & 3,77 & 90589 & \\
\hline \multirow[t]{3}{*}{ SDEM interface } & Webcast & 176 & 3,71 & ,65298 & \multirow{3}{*}{0.030} \\
\hline & Video & 224 & 3,50 & ,85589 & \\
\hline & Hypertext & 93 & 3,6 & ,79051 & \\
\hline
\end{tabular}




\subsection{SDEM content}

Initially, the content construct was examined with respect to the type of SDEM. Results indicate that Hypertext presents the biggest challenge since $18 \%$ of the students have absolutely negative views of SDEM content comprehensibility using this means. On the other hand, Webcast and Video are more accessible to students since the absolutely negative views hover around $7 \%$. (see Chart 1 )

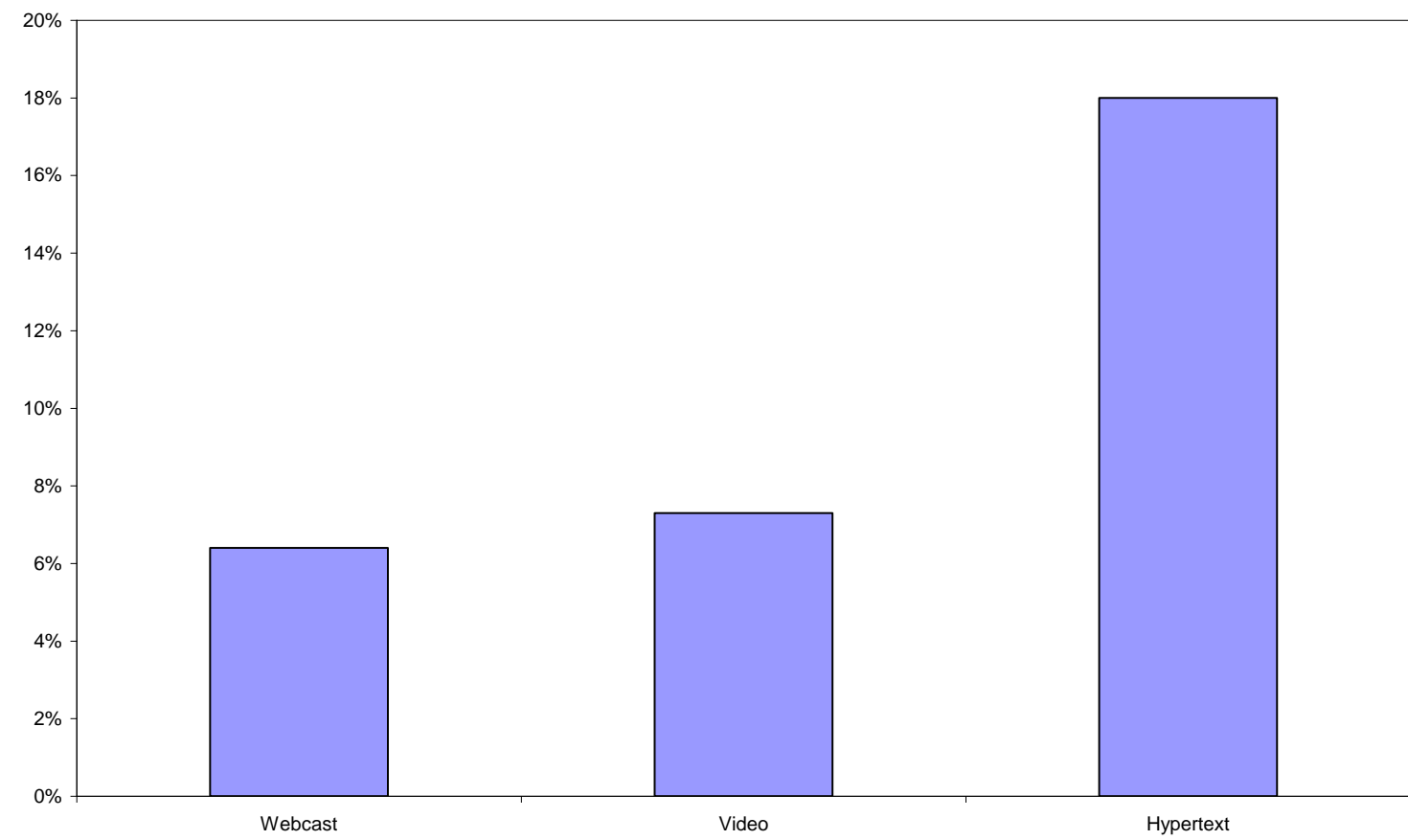

Chart 1: Percentages of absolutely negative views of SDEM content comprehensibility with respect to its type

Similarly, postgraduate students have substantially greater difficulty with SDEM content comprehensibility with $17.3 \%$ of them offering an absolutely negative assessment compared to just $7 \%$ of the undergraduate students (see Chart 2). 


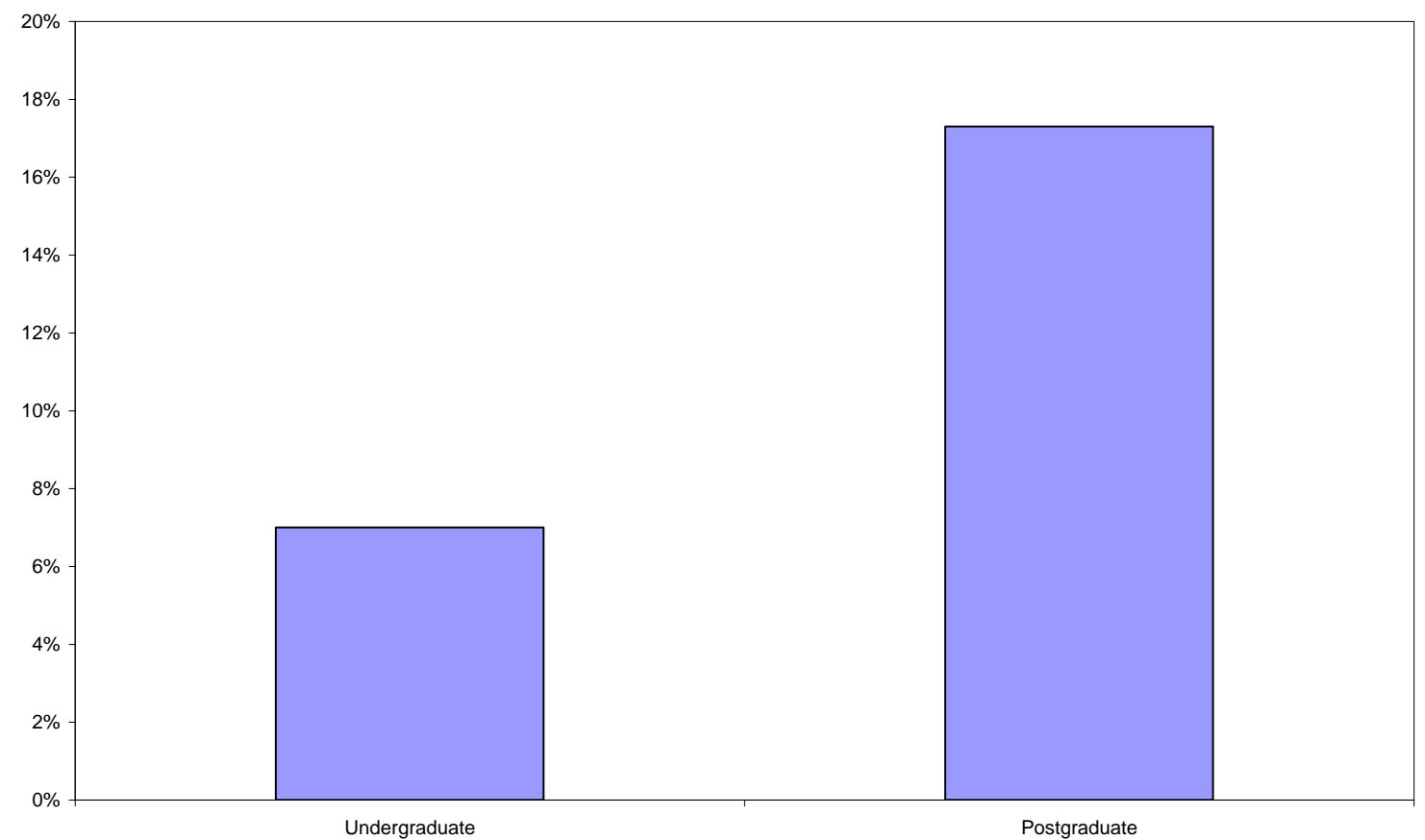

Chart 2: Percentages of absolutely negative views of SDEM content comprehensibility with respect to student level

Important aspects of SDEM pertain to its clarity and accuracy as well as to its association with the corresponding print-based educational material. Once again hypertext-type material displays the highest percentage of absolutely negative views concerning clarity and accuracy (12.9\%) compared to the negative values for Webcast and Video $(\approx 2 \%)$. Similarly, the association between SDEM and the print-based material is viewed most negatively among postgraduate students $(8.5 \%$ to $2 \%)$ and when the digitized material is in hypertext format (10\% to around $2 \%-3 \%)$.

\subsection{SDEM instructional and pedagogical methodology}

There is a variation in the emphasis SDEM places on the material's core concepts of the discipline. More specifically, as illustrated in Chart 3, Hypertext has again the highest percentage of negative responses (24\%) compared to Webcast (8.3\%) and Video $(7 \%)$. Webcast also possesses the highest portion of positive responses $(21 \%$ compared to $11 \%$ for the other two means). Finally, postgraduate students demonstrate a higher percentage of negative answers (8.2\% to $1.2 \%$, see Chart 4$)$. 


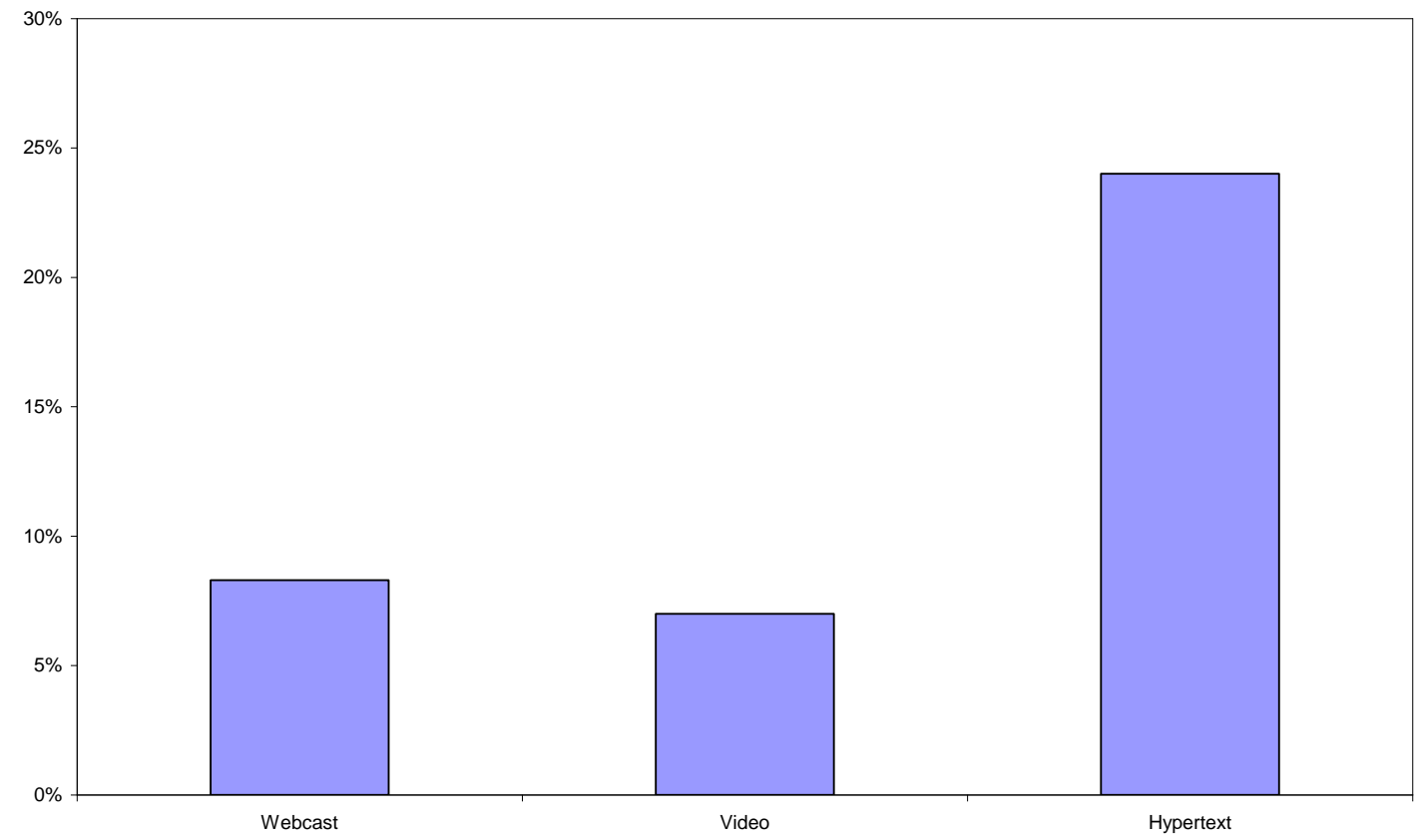

Chart 3: Percentages of absolutely negative views of SDEM emphasis on core concepts of the discipline with respect to its type

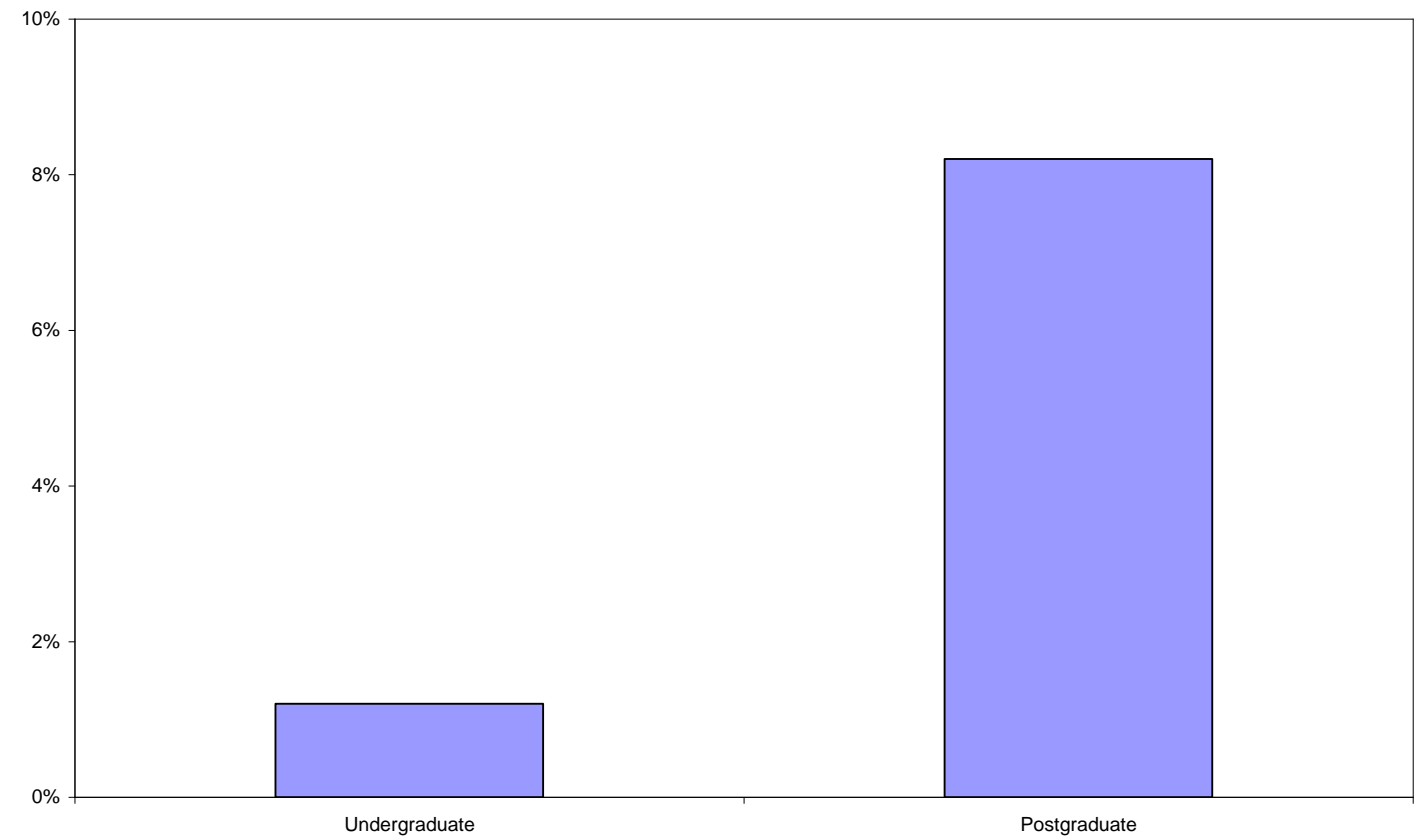

Chart 4: Percentages of absolutely negative views of SDEM emphasis on core concepts of the discipline with respect to student level

As illustrated in Chart 5, reporting learning objectives in SDEM revealed mixed responses with similar levels of absolutely positive and negative responses in Hypertext (14.3\% is the proportion of absolutely negative answers) compared to the other two SDEM types (approximately 3\% of absolutely negative answers). Furthermore, Webcast shows the highest percentage of absolutely positive answers (18\%) followed by Hypertext $(11 \%)$ and Video (9\%). In terms of student level, 
postgraduate students have higher levels of absolutely negative responses than undergraduate students (14,6\% to $2.6 \%$, see Chart 6).

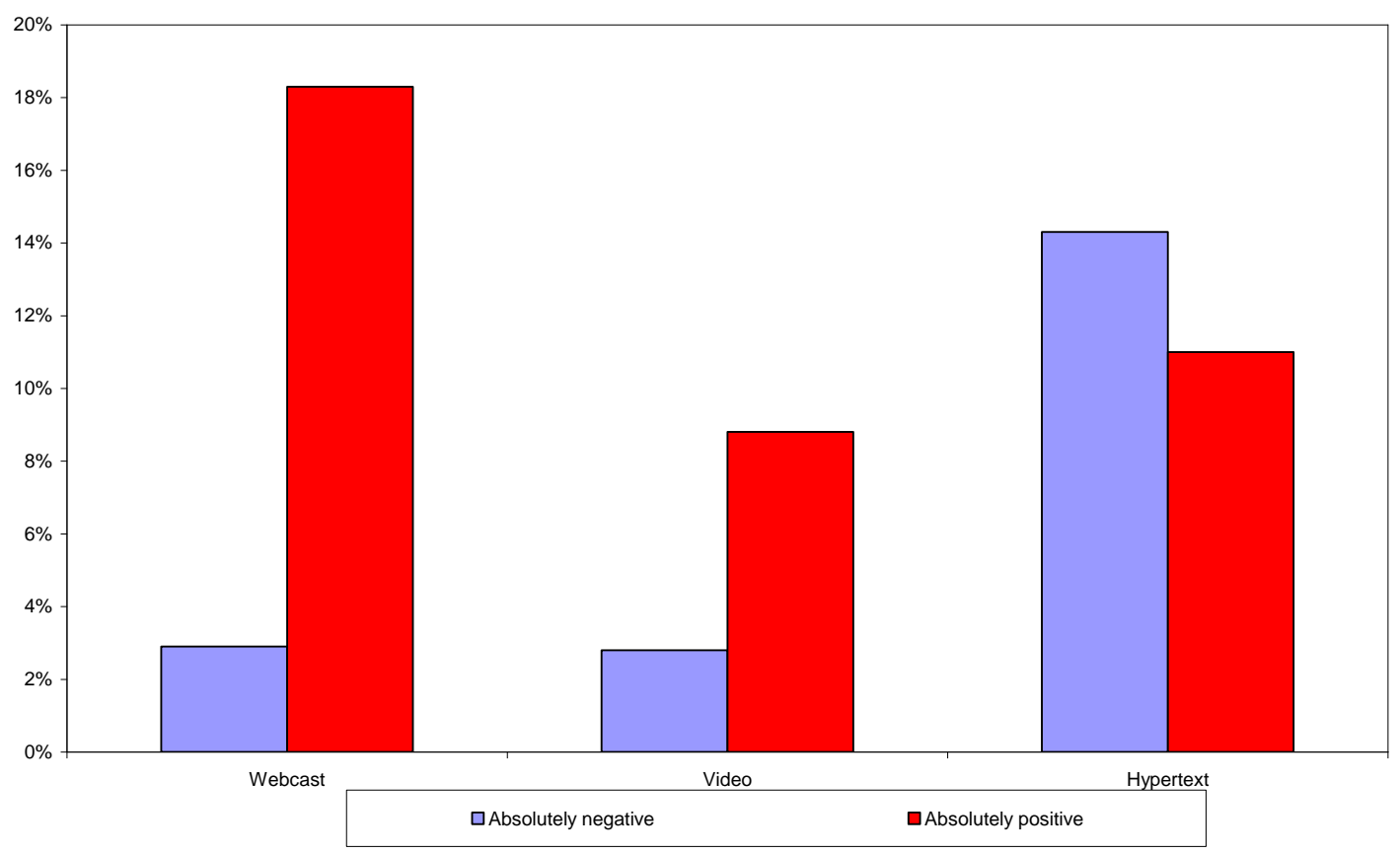

Chart 5: Percentages of absolutely negative views / absolutely positive views of SDEM inclusion of learning objectives with respect to its type

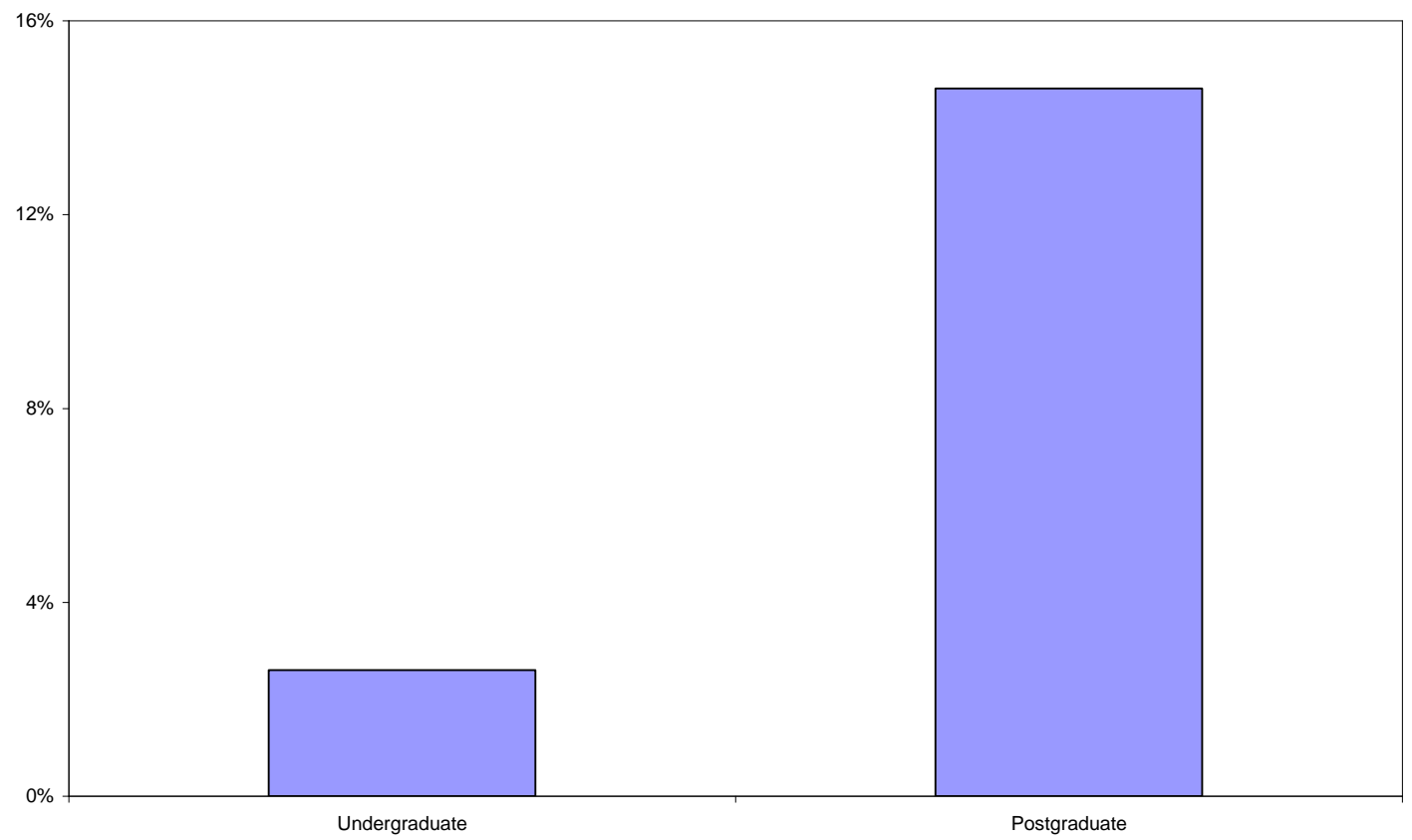

Chart 6: Percentages of absolutely negative views of SDEM inclusion of learning objectives with respect to student level

Concerning the achievement of learning objectives in SDEM, we note that Hypertext draws the biggest percentage of both absolutely negative and absolutely positive views (5\% and 33\% respectively, see Chart 7). Postgraduate students also 
have a higher percentage of negative values concerning the accomplishment of learning objectives ( $15.6 \%$ to $4.4 \%$, see Chart 8 ).

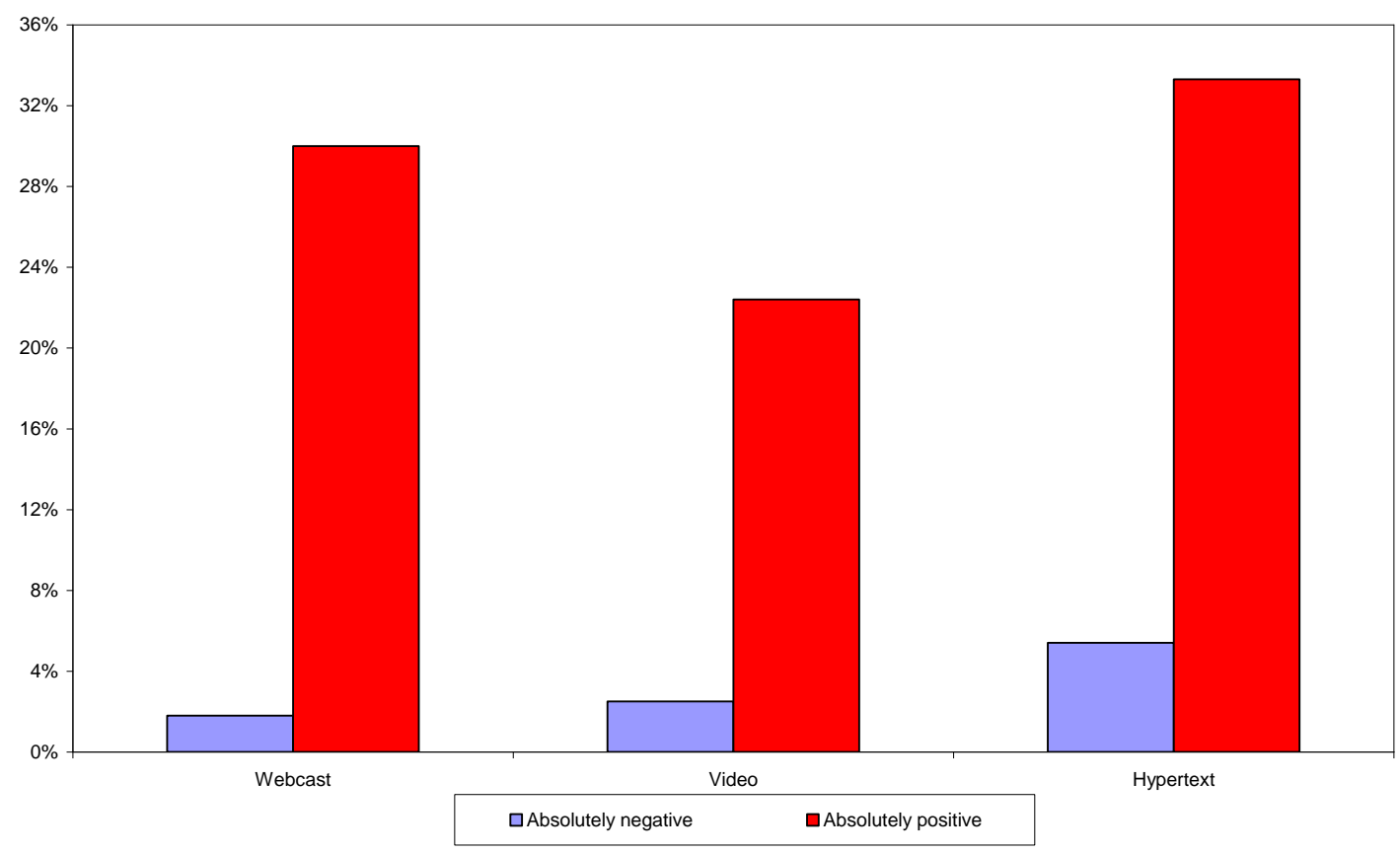

Chart 7: Percentages of absolutely negative views / absolutely positive views of SDEM achievement of learning objectives with respect to its type

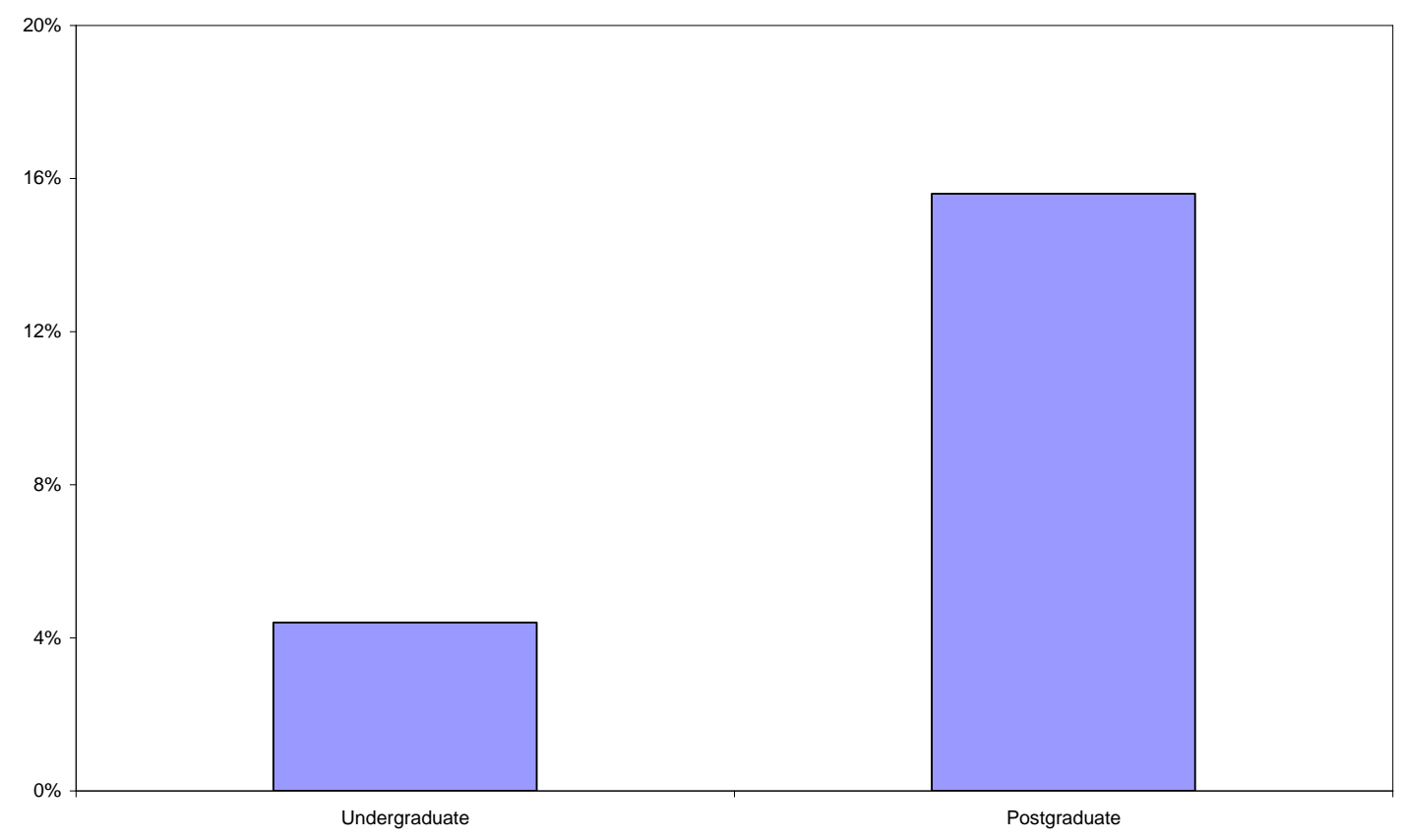

Chart 8: Percentages of absolutely negative views of SDEM achievement of learning objectives with respect to student level

An important distinction is again drawn to the SDEM learning process approach. Hypertext is the least effective type in active (23\% of absolutely negative views), critical $(17 \%)$ or creative learning $(22 \%)$ whereas Webcast is usually the most effective $(24.3 \%, 18 \%$ and $18.6 \%$ respectively of absolutely positive views) followed 
closely by Video (19\%, $18 \%$ and $14.9 \%$ respectively). The above trend does not alter considerably when SDEM encouragement of problem solving through practical applications is concerned with the exception of Video replacing Webcast as the most effective type. In all of the above categories, postgraduate students have the higher percentage of negative responses.

\subsection{SDEM technical specifications \& interface}

SDEM screen layout is unappealing (16.3\%) and difficult to understand $(9.4 \%)$ by postgraduate students whereas undergraduate students are more receptive $(6 \%$ and $1.6 \%$ respectively). Multimedia use is nonexistent with almost one third of the postgraduate students $(32.1 \%$ ) compared to just $2.7 \%$ of the undergraduate students). Almost $53 \%$ of the undergraduate students responded positively about the availability of an instruction manual compared to only $35.1 \%$ of the postgraduate students. Hardware specifications are present in Webcast (84.6\%), Hypertext $(74.5 \%)$ and Video $(61.8 \%)$. SDEM installation is rather easy especially in hypertext form (54.2\%) followed by Webcast (44.8\%) and Video (34\%).

\section{Concluding Remarks}

This study aimed at examining students' views about different quality dimensions of the SDEM provided by the HOU. It also intended to explore the relationship between students' views concerning SDEM quality with (a) the type of SDEM (Webcast, Video, Hypertext) and (b) the level of the students' studies (undergraduate, postgraduate).

The analysis of the students' responses revealed that their views were overall rather positive. However, the results pointed out certain aspects of SDEM that need to be addressed by the HOU. More specifically, with respect to the dimension of its content presentation, students tend to see shortcomings concerning the comprehensibility, the clarity and accuracy of the SDEM content as well as SDEM accordance with the corresponding print-based educational material. Significant instructional and pedagogical characteristics of the SDEM, such as the explicit presentation of the learning objectives and the promotion of active, critical or creative learning, appeared not to be reflected with regard to the SDEM examined.

Moreover, an important research finding is that Hypertext material does not seem to be effective. This conclusion is omnipresent in most content-related and pedagogical SDEM dimensions. Of the other two SDEM types, Webcast is viewed more favorably especially with regard to pedagogical aspects. Furthermore, it is imperative to note that postgraduate students face serious challenges in dealing with SDEM not only in terms of its educational aspects but also with respect to the material's technical requirements, albeit to a lesser extent.

It is worth mentioning that although the present study's findings have a special informational value regarding the quality of the developed SDEM, a follow-up of the whole evaluation procedure spanning uniformly more modules would provide robust results and help the HOU in properly modifying SDEM.

Even though these results do not seem extremely optimistic, one has to keep in mind that until recently there was no use whatsoever of digitized educational material in tertiary education, let alone at the HOU. Thus, creating and simply disseminating a new type of educational material is only the first step in establishing a new teaching and learning culture that enables the use of more than just the time-honored textbook. 
The next steps should focus on more -and more comprehensive- research and discussion within the HOU from the perspective of two levels. The first level concerns the future design and development of digitized educational material on the basis of the available pedagogical research findings. More specifically, the findings of the present study along with the available relevant literature will assist those that are involved with the HOU's development to improve the quality of the existing educational materials which, in turn, will be used in educational practice and then will be re-evaluated in order to reach a higher efficiency level.

Taking into account the results of the present study along with the module coordinators' views on SDEM's marginal role in the instructional processes (HOU, 2008), the second level should focus on the issue of integrating SDEM in these processes in such an operational way as to fulfill its programmatic objective, i.e. to complement the existing printed material forming a cohesive educational package for modules.

\section{Acknowledgements}

This paper is based on a research project funded principally by the Operational Programme for Education and Initial Vocational Training (EPEAEK-II) and supported by the HOU's Governing Board (Action 9 of the Project: "Development and improvement of the services provided by the Hellenic Open University"). Scientific project leader was the Emeritus Professor Th. Patargias, member of the Governing Board of the HOU. The educational research team and the informatics team included: A. Chatzilakos, Ch. Dimopoulou, A. Emvalotis, V. Hatzinikita, D. Kalles, D. Karaiskakis, A. Katsis, K. Petrogiannis, Ch. Pierrakeas, D. Stavrinoudis, N. Trifona, and M. Xenos.

The authors would like to express their appreciation to undergraduate and postgraduate students as well as the module coordinators of the HOU that participated in the study. The authors would also like to acknowledge the supportive staff of the HOU Registry Office for the constant provision of all the information and data that were necessary for the accomplishment of this study.

\section{References}

Bailey, J. E., \& Pearson, S. W. (1983). Development of a tool for measuring and analyzing computer user satisfaction. Management Science, 29 (5), 530-545.

Barbier, J.- M. (1985). L'évaluation en formation. Paris: PUF.

Barker, P., King, T. (1993). Evaluating interactive multimedia courseware: a methodology. Computers \& Education, 21 (4), 307-3 19.

Barker, T., \& Barker, J. (2002). The evaluation of complex, intelligent, interactive, individualised human-computer interfaces: what do we mean by reliability and validity?. In Proceedings of the 7th learning styles conference. Belgium: University of Ghent - European Learning Styles Information Network (ELSIN).

Blalock, H. M. (1987). Social statistics. Singapore: McGraw-Hill.

Blease, D. (1986). Evaluating educational software. London: Croom Helm

Boyle, A., \& O'Hare, D. (2003). Finding appropriate methods to assure quality computer-based development in UK higher education. In Proceedings of the 7th computer-assisted assessment conference. United Kingdom: Loughborough University.

Brouwer-Janse, M. D., \& Harrington, T. L. (1994). Human-machine communication for educational systems design. Berlin, New York: Springer-Verlag.

Brownstein, I., \& Lerner, N. B. (1982). Guidelines for evaluating and selecting software packages. New York: Elsevier.

Burgess, R.G. (1985). Strategies of educational research: qualitative methods. London: The Falmer Press. 
Clements, P., Kazman, R., \& Klein, M. (2002). Evaluating software architectures: methods and case studies. Boston: Addison-Wesley.

Cohen, L., Manion, L., \& Morrison, K. (2007). Research methods in education (6th ed.). London, New York: Routledge.

Denzin, N. K., \& Lincoln, Y. S. (1994). Handbook of qualitative research. Thousand Oaks, Calif: Sage Publications.

Denzin, N. K., \& Lincoln, Y. S. (1998a). Strategies of qualitative inquiry. Thousand Oaks, Calif.: Sage Publications.

Denzin, N. K., \& Lincoln, Y. S. (1998b). The landscape of qualitative research: theories and issues. Thousand Oaks, CA: Sage Publications.

Doll, C. (1987). Evaluating educational software. Chicago: American Library Association.

Erickson, B., \& Nosanchuk, T. (1985). Understanding data. Milton Keynes: Open University Press.

Hammerseley, M. (Ed). (1993). Social Research. Thousand Oaks, California: Sage.

Hammersley, M. (1989). The dilemma of qualitative method. London, New York: Routledge.

Holmberg, B. (1989). Theory and practice of distance education. London and New York: Routledge.

Hellenic Open University (2008). Development and improvement of the Hellenic Open University's provision of educational services (Action 9). Unpublished Final Technical Report. Patras: Hellenic Open University.

Johnson, B., \& Christensen, L. B. (2004). Educational research: quantitative, qualitative, and mixed approaches (2nd ed.). Boston: Allyn and Bacon.

Komis, B. (2004). Introduction to educational applications of information and communication. Athens: New Technologies. [in Greek]

Komis, B., \& Mikropoulos, A. (2001). Informatics in education. Patras: Hellenic Open University. [in Greek]

Koustourakis, G., Panagiotakopoulos, C., \& Vergidis, D. (2008). A contribution to the Hellenic Open University: evaluation of the pedagogical practices and the use of ICT on distance education. The International Review of Research in Open and Distance Learning, 9(2). [http://www.irrodl.org/index.php/irrodl/article/view/424]

Lionarakis, A. (2001). Qualitative approaches in the design and production of multimedia educational material for distance education. In B. Makrakis (Ed.), Proceedings of the Conference "New technologies in education and distance education" (pp. 47-54). Department of Primary Education, University of Crete, Rethymnon. [in Greek]

Lionarakis, A. (2004). A pedagogical model for the design and production of instructional multimedia material for distance education. In I. Kekkes (Ed.), New technologies in education - Issues of design and application: Philosophical - Social extensions (pp. 53 - 74). Athens: Union of Greek Physicists - Atrapos. [in Greek]

Lykourgiotis, A. (2002). Development of the supplementary educational material in the context of the $2^{\text {nd }}$ EPEAEK. Unpublished text for the HOU tutors. Patras: Hellenic Open University. [in Greek]

Mahmood, M. A., Burn, J. M., Gemoets, L. A., \& Jacquez, C. (2000). Variables affecting information technology end-user satisfaction: a meta-analysis of the empirical literature. International Journal of Human-Computer Studies, 52 (4), 751-771.

Makrakis, B. (1998). Theoretical context and types of evaluation. In D. Vergidis, A. Lionarakis, A. Lykourgiotis, B. Makrakis, \& Ch. Matralis (Eds.), Open and distance education: Institutions and operations (pp. 245-290). Patras: Hellenic Open University. [in Greek]

Meade, J. (2003). The human resources software handbook: evaluating technology solutions for your organization. San Francisco: Jossey Bass.

Melone, N. P. (1990). A theoretical assessment of the user-satisfaction construct in information systems research. Management Science, 36(1), 76-91.

Mikropoulos, A. (2000). Educational software: Issues of design and evaluation of hypermedia software. Athens: Kleidarithmos. [in Greek]

Ministry of Education and Religious Affairs - Pedagogical Institute (1999). Technologies of information and communication in education. Athens: Pedagogical Institute. [in Greek]

Nunnaly, J. (1978). Psychometric theory. New York: McGraw-Hill.

Panagiotakopoulos, Ch., Pierrakeas, Ch., \& Pintelas, P. (2003). Educational software and its evaluation. Athens: Metaichmio. [in Greek]

Panagiotakopoulos, Ch., Pierrakeas, Ch., \& Pintelas, P. (2004). Design of educational software. Patras: Hellenic Open University. [in Greek]

Patton, M. Q. (1991). Qualitative evaluation and research methods. London: Sage.

Peat, M., \& Franklin, S. (2002). Supporting student learning: the use of computer-based formative assessment modules. British Journal of Educational Technology, 33, 515-523. 
Perrenoud, P. (1998). From formative evaluation to a controlled regulation of learning processes. Towards a wider conceptual field. Assessment in Education, 5, 85-102.

Pierrakeas, Ch., Xenos, M., \& Pintelas, P. (2003). Evaluating and improving educational material and tutoring aspects of distance learning systems. Studies in Educational Evaluation, 29 (4), 335-349.

Pierrakeas, Ch., Xenos, M., \& Pintelas, P. (2005). Evaluating and improving educational material and tutoring aspects of distance learning systems. Studies in Educational Evaluation, 29 (4), 335-349.

Preece, J., Rogers, Y., \& Sharp, H. (2002). Interaction design: Beyond human-computer interaction. New Jersey: Wiley.

Reeves, T. C., \& Harmon, S. W. (1994). Systematic evaluation procedures for interactive multimedia for education and training. In: S. Reisman (Ed.), Multimedia computing: preparing for the 21 st century (p. 472-505). Harrisburg, PA: Idea Group Publishing.

Reeves, T. C., \& Hedberg, J. G. (2002). Interactive learning systems evaluation. Engelwood Cliffs, NJ: Educational Technology Press.

Robson, C. (2002). Real world research: A Resource for Social Scientists and PractitionerResearchers. UK: Blackwell Publishing Ltd.

Scriven, M. (1967). The methodology of evaluation. Washington DC: American Educational Research Association).

Sloane, H. N., \& Learning Technology Associates. (1989). Evaluating educational software: a guide for teachers. Englewood Cliffs, N.J.: Prentice Hall.

Squires, D., \& McDougall, A. (1994). Choosing and using educational software: a teachers' guide. London, Washington, D.C: Falmer Press.

Wang, T. H. (2007). What strategies are effective for formative assessment in an e-Learning environment?. Journal of Computer Assisted Learning, 23, 171-186.

\section{Notes}

${ }^{1}$ According to the Act 2552 the core operational teaching unit of the HOU is the Module, which covers a distinct academic field in an undergraduate or postgraduate level. Every module is equivalent to three semestrial courses of the traditional university departments.

${ }^{2}$ The scientific coordination was under Emeritus Professor Th. Patargias, member of the Governing Board of the HOU. The evaluation study was undertaken by the following teams: (a) Educational Research team: V. Hatzinikita (leader), A. Katsis, K. Petrogiannis, A. Emvalotis, (b) Informatics team: A. Chatzilakos (leader), M. Xenos, D. Stavrinoudis, D. Karaiskakis, Ch. Pierrakeas, D. Kalles, Ch. Dimopoulou, and N. Trifona.

${ }^{3}$ EPEAEK: Operational Programme for Education and Initial Vocational Training.

${ }^{4}$ For a detailed description of the SDEM's evaluation project see Hellenic Open University (2008).

${ }^{5}$ See for example: Barker \& Barker, 2002; Barker \& King, 1993; Bailey \& Pearson, 1983; Blease, 1986; Boyle \& O’Hare, 2003; Brownstein \& Lerner, 1982; Brouwer \& Harrington, 1994; Brownstein \& Lerner, 1982; Clements et al., 2002; Doll, 1987; Komis, 2004; Komis \& Mikropoulos, 2001; Makrakis, 1998; Mikropoulos, 2000; Mahmood et al., 2000; Meade, 2003; Melone, 1990; Panagiotakopoulos et al., 2003, 2004; Pierrakeas et al., 2003; Pea \& Franklin, 2002; Phillips et al., 2000; Perrenoud, 1998; Preece et al., 2002; Raptis \& Rapti, 1996; Reeves \& Harmon, 1994; Reeves \& Hedberg, 2002; Sloane \& Learning Technology Associates, 1989; Squires \& McDougall, 1994; Wang, 2007.

${ }^{6}$ Master in Teaching English as a Foreign Language (AGG52, AGG67, AGG68), Master in Adult Education (EKE50), Master in Teaching Natural Sciences (KFE51, KFE52, KFE53), Business Administration (DEO23, DEO33), Studies in Natural Sciences (FYE10, FYE12, FYE14, FYE20, FYE22, FYE24, FYE30, FYE31, FYE34, FYE40, FYEXI, FYEXII). 